Imanishi, H. and D. Yue. 1985. Effects of duration of exposure to ethylene on flowering of Dutch iris. Acta Hort. 177:141-145.

Kohl, H.C. 1967. Correlation between rate of initiation and apex diameter of Lilium longiflorum cultivar 'Ace'. HortScience 2:15-16.

Reid, M.S. 1987. Ethylene in plant growth, development, and senescence. p. 257-279. In: P.J. Davies (ed.). Plant hormones and their roles in plant growth and development. Martinus Nijhoff, Boston.

Reid, M.S. and H.K. Pratt. 1972. Effects of ethylene on potato tuber respiration. Plant Physiol. 49:252-255.

Sachs, R.M. 1977. Nutrient diversion: An hypothesis to explain the chemical control of flowering. HortScience 12:220-222.

Schipper, J.A. 1982. A smoke treatment inducing flower formation in iris bulbs. Netherlands J. Agr. Sci. 29:173-177.
Uyemura, S. and H. Imanishi. 1983. Effects of gaseous compounds in smoke on dormancy release in freesia corms. Scientia Hort. 20:9199.

Uyemura, S. and H. Imanishi. 1984. Effects of duration of exposure to ethylene on dormancy release in freesia corms. Scientia Hort. 22:383-390.

Vacha, G.A. and R.B. Harvey. 1927. The use of ethylene, propylene and similar compounds in breaking the rest Period of tubers, bulbs, cuttings, and seeds. Plant Physiol. 2:187-193.

Yemm, E.W. and A.J. Willis. 1954. The estimation of carbohydrates in plant extracts by anthrone. Biochem. J. 47:508-514.

J. Amer. SOC. HorT. SCI. 115(3):486-491. 1990

\title{
A Model for Net Photosynthesis of Rose Leaves as a Function of Photosynthetically Active Radiation, Leaf Temperature, and Leaf Age
}

\author{
J.H. Lieth ${ }^{1}$ and C.C. Pasian ${ }^{2}$ \\ Department of Environmental Horticulture, University of California, Davis, CA 95616 \\ Additional index words. Rosa hybrida, mathematical model, irradiance
}

\begin{abstract}
A mathematical description for the relationship between the rate of rose (Rosa hybrida L.) leaf net photosynthesis and photosynthetically active radiation, leaf temperature, and leaf age is developed. The model provides a tool for the prediction of these rates for leaves growing in a rose crop canopy.
\end{abstract}

Mathematical crop models are valuable tools for optimizing production practices for many agronomic crops (Whisler et al., 1986). Such models predict crop growth and development in response to environmental factors such as irradiance, temperature, and $\mathrm{CO}_{2}$ concentration. One of the most feasible approaches in developing crop simulation models is to use modules (Reynolds et al., 1988) where each module focuses exclusively on one physiological phenomenon. Typically, there are modules for photosynthesis, respiration, assimilate partitioning, and various other processes that may be of specific interest, such as fruit or leaf abscission. This paper describes the development of one such module for a rose crop model: a net leaf photosynthesis model responsive to photosynthetically active radiation (PAR), leaf temperature, and leaf age.

Aikin and Hanan (1975) and Bozarth et al. (1982) measured the photosynthetic response of roses to irradiance. Both observed a pattern of saturation with increasing light levels. We (Pasian and Lieth, 1989) found a non-rectangular hyperbola to be a suitable mathematical description of the PAR response of rose leaves. We investigated the suitability of this model at various combinations of four temperatures and leaf ages and indicated that additional data over a wider range of leaf temperatures and ages were needed to incorporate these variables into the model.

Additional environmental variables can be incorporated into such a photosynthesis PAR response model by letting the sat-

Received for publication 28 Nov. 1988. This project was funded in part by a grant from the Joseph H. Hill Memorial Foundation and Roses Incorporated. The cost of publishing this paper was defrayed in part by the payment of page charges. Under postal regulations, this paper therefore must be hereby marked advertisement solely to indicate this fact.

${ }^{1}$ Assistant Professor and Extension Specialist.

${ }^{2}$ Graduate Research Assistant. urated net photosynthetic rate $\left(\mathrm{P}_{\mathrm{m}}\right)$, usually a parameter in such a model, vary with these variables. This approach is possible for leaf temperature because its effect on net photosynthesis is manifested mainly through its effect on $\mathrm{P}_{\mathrm{m}}$ (Johnson and Thornley, 1984). Leaf age has also been shown to have an impact on $\mathrm{P}_{\mathrm{m}}$ (Catsky and Ticha, 1980; Constable and Rawson, 1980; Field and Mooney, 1983) so that it can be dealt with in the same way. The objectives of this study were to: 1) supplement our earlier data (Pasian and Lieth, 1989); 2) formulate a mathematical model for net photosynthesis incorporating PAR, leaf temperature, and leaf age; and 3) calibrate this model.

\section{Materials and Methods}

All net 'Cara Mia' rose leaf photosynthesis rates were collected using a LI-COR 6000 photosynthesis meter (LI-COR, Lincoln, Neb.) (Pasian and Lieth, 1989). Plants were grown in containers in a greenhouse and moved to the site where measurements were to take place (usually a growth chamber). Measurements were made under a 1000-W metal-halide lamp suspended in a structure consisting of a metal tube framework.

Temperature response. Net $\mathrm{CO}_{2}$ exchange rates of 20-dayold leaves at light saturation were collected with leaves at temperatures $>37 \mathrm{C}$ and $<10 \mathrm{C}$. Growth chambers were used to provide conditions resulting in leaf temperatures up to $37 \mathrm{C}$. Leaf temperatures $>37 \mathrm{C}$ were attained by placing the frame and lamp, covered with black cloth, in direct sunlight outdoors on hot, sunny days during Aug. 1986 in Davis, Calif. While no sunlight penetrated to the leaves, the combination of high air temperature, long-wave radiation absorbed by the black cloth reradiating to the plant, radiation of heat from the lamp, and reduced air circulation resulted in controllable leaf temperatures ranging from 35 to $50 \mathrm{C}$. The interior of the structure was sprayed with deionized water every $5 \mathrm{~min}$ with a spray bottle so that the relative humidity (measured by the LI-COR 6000) was at least $30 \%$ for 


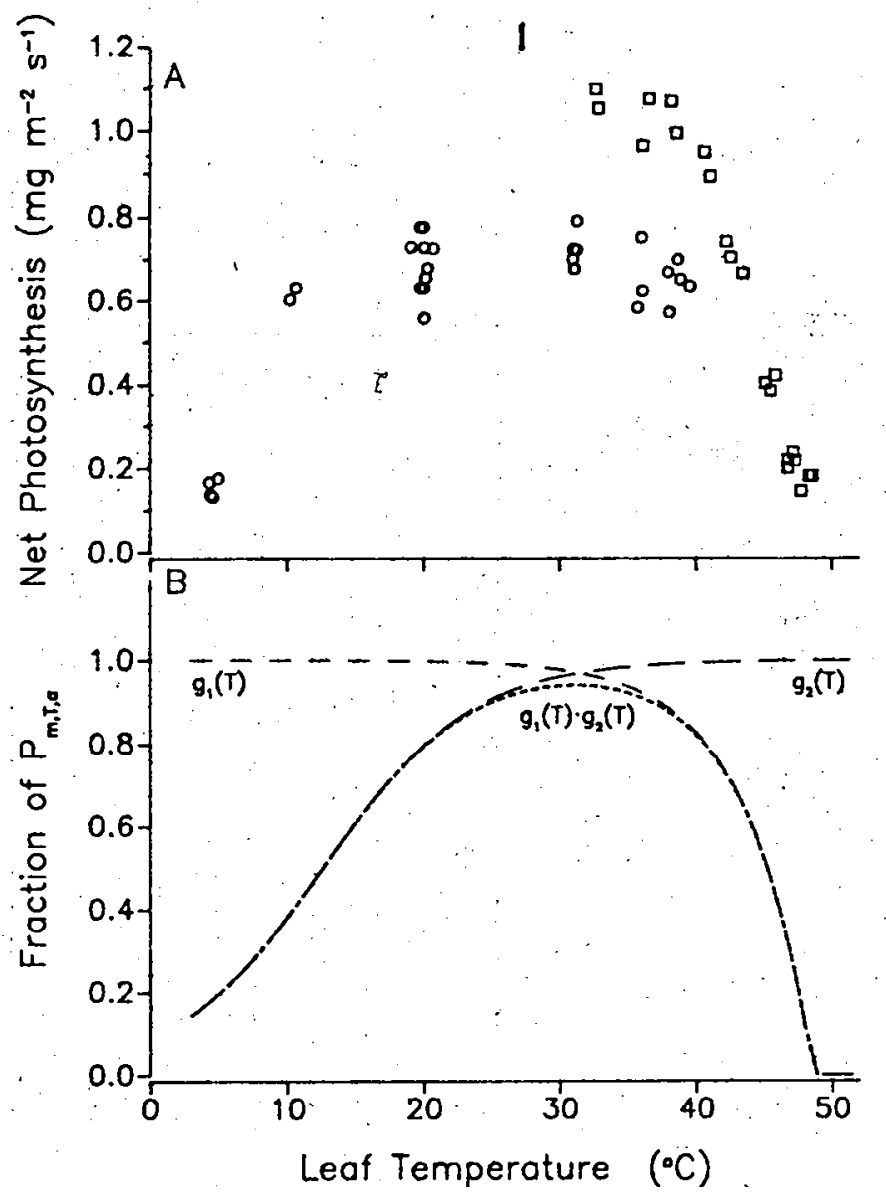

Fig. 1. (A) Leaf net photosynthesis rates for temperatures $<40 \mathrm{C}$ measured in a growth chamber. (circles) and for temperatures $>35 \mathrm{C}$ observed outdoors (squares), as described in text. (B) Graphs of $\mathrm{g}$, $(\mathrm{T})$ (with $\mathrm{b}_{1}=2.33$ and $\mathrm{b}_{2}=0.185$ ) and $\mathrm{g}_{2}(\mathrm{~T})$ (with $\mathrm{b}_{3}=0.204$ ) and their product.

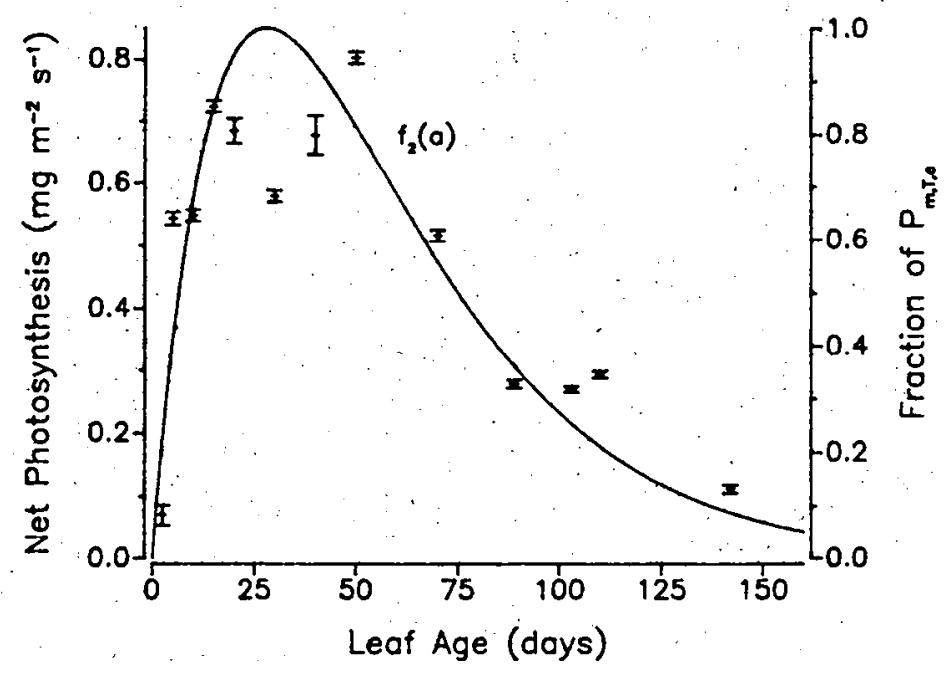

Fig. 2. Averages and SE bars for rose leaf net photosynthesis rates for leaf temperatures between 18 and $22 \mathrm{C}$ at photosynthetically active radiation levels between 600 and $750 \mu \mathrm{mol} \cdot \mathrm{s}^{-1} \cdot \mathrm{m}^{-2}$. The curve is $f_{2}(a)$ with $b_{4}=0.0357$.

each $\mathrm{CO}_{2}$ exchange measurement. Net photosynthesis rates at photosynthetic photon flux densities (PPFD) $>600 \mu \mathrm{mol} \cdot \mathrm{s}^{-1} \cdot \mathrm{m}^{-2}$ were collected using three different leaves on different days.
Table 1. Nonlinear least-squares summary statistics from fitting the model for $\mathrm{P}_{\mathrm{n}}\left(\mathrm{mg} \cdot \mathrm{s}^{-1} \cdot \mathrm{m}^{-2}\right)$ to the data. In this fitting, $\mathrm{T}_{\mathrm{d}}$ and $\mathrm{c}_{2}$ were fixed at $48.6 \mathrm{C}$ and $0 \mathrm{mg} \cdot \mathrm{s}^{-1} \cdot \mathrm{m}^{-2} \cdot$ day $^{-1}$, respectively.

\begin{tabular}{|c|c|c|c|c|}
\hline \multicolumn{5}{|c|}{ Analysis of variance } \\
\hline Source & & \multicolumn{2}{|c|}{ df } & $\begin{array}{l}\text { Sum of } \\
\text { squares }\end{array}$ \\
\hline Regression & & \multicolumn{2}{|c|}{9} & 129.41 \\
\hline Residual & & \multicolumn{2}{|c|}{601} & 4.68 \\
\hline Uncorrecte & total & \multicolumn{2}{|c|}{610} & 134.10 \\
\hline \multicolumn{5}{|c|}{ Parameter estimates } \\
\hline \multirow[b]{2}{*}{ Parameter } & \multirow[b]{2}{*}{ Estimate } & \multirow{2}{*}{$\begin{array}{l}\text { Asymptotic } \\
\text { SE }\end{array}$} & \multicolumn{2}{|c|}{ Asymptotic $95 \% \mathrm{CI}$} \\
\hline & & & L_ower & Upper \\
\hline$\alpha$ & 0.00341 & 0.00040 & 0.00263 & 0.00418 \\
\hline$P_{m . T, a}$ & 1.03 & 0.07 & 0.90 & 1.16 \\
\hline$\theta^{\mathrm{m} \cdot 1, \mathrm{~s}}$ & 0.479 & 0.166 & 0.153 & 0.804 \\
\hline$b_{1}$ & 2.33 & 0.22 & 1.90 & 2.75 \\
\hline$b_{2}$ & 0.185 & 0.019 & 0.148 & 0.223 \\
\hline $\mathrm{b}_{3}$ & 0.204 & 0.041 & 0.123 & 0.284 \\
\hline$b_{4}$ & 0.0357 & 0.0007 & 0.0343 & 0.0372 \\
\hline$c_{0}$ & -0.0929 & 0.0204 & -0.1330 & -0.0529 \\
\hline$c_{1}$ & 0.00351 & 0.00073 & 0.00208 & 0.00494 \\
\hline
\end{tabular}

Leaf age effect. $\mathrm{P}_{\mathrm{m}}$ values at 20C were measured on 12 leaves of ages $1,3,5,15,30,50,70,89,103,110$, and 142 days to supplement the existing data for ages 10, 20, 30, and 40 days. Leaf age was determined as the number of days since the date on which the leaflet unfolded. Six to eight photosynthetic measurements at PPFD of between 600 and $750 \mu \mathrm{mol} \cdot \mathrm{s}^{-1} \cdot \mathrm{m}^{-2}$ were made for each selected leaf.

\section{Results}

Model development. The equation of the non-rectangular hyperbola (Thornley, 1976; Marshall and Biscoe, 1980), found to be suitable for rose leaf net $\mathrm{CO}_{2}$ exchange by Pasian and Lieth (1989), is:

$$
P_{n}=\frac{\alpha I+P_{m}-\sqrt{\left(\alpha I+P_{m}\right)^{2}-4 \alpha I P_{m}^{\theta}}}{2 \theta}-R_{d}
$$

where $\alpha$ is photosynthetic efficiency, $\mathrm{I}$ is PPFD, $\mathrm{P}_{\mathrm{m}}$ is PAR saturated rate of net photosynthesis, $\theta$ is a parameter, and $R_{d}$ is leaf dark respiration. Leaf temperature and age can be incorporated by replacing $\mathrm{P}_{\mathrm{m}}$ with a function of leaf temperature (T) and leaf age (a). Assuming that these two effects are separate, this function takes the form:

$$
P_{m}(T, a)=P_{m, T, a} \cdot f_{1}(T) \cdot f_{2}(a)
$$

$\mathrm{P}_{\mathrm{m}, \mathrm{T}, \mathrm{a}}$ is defined as the maximum net photosynthetic rate per unit leaf area over all PPFD levels, temperature, and ages. f,(T) is a mathematical function describing the reduction from this absolute maximum due to leaf temperature. Similarly, $\mathrm{f}_{2}(\mathrm{a})$ is a function describing such a pattern for leaf age (a). The terms $f_{1}(T)$ and $f_{2}(a)$ must be selected to take on values between 0 and 1 so that $P_{m}(T, a)$ will vary between 0 and $P_{m, T, a} ; f_{1}(T)$ and $f_{2}$ (a) can be constructed by considering $P_{n}$ data at high PAR for a fixed level of a and $\mathrm{T}$, respectively.

Dark respiration $\left(\mathrm{R}_{\mathrm{d}}\right)$ has been observed to increase with temperature in various species (Penning de Vries et al., 1979; Gent and Enoch, 1983), including roses (Pasian and Lieth, 1989). Variations in $\mathrm{R}_{\mathrm{d}}$ with age have been observed in coffee and 


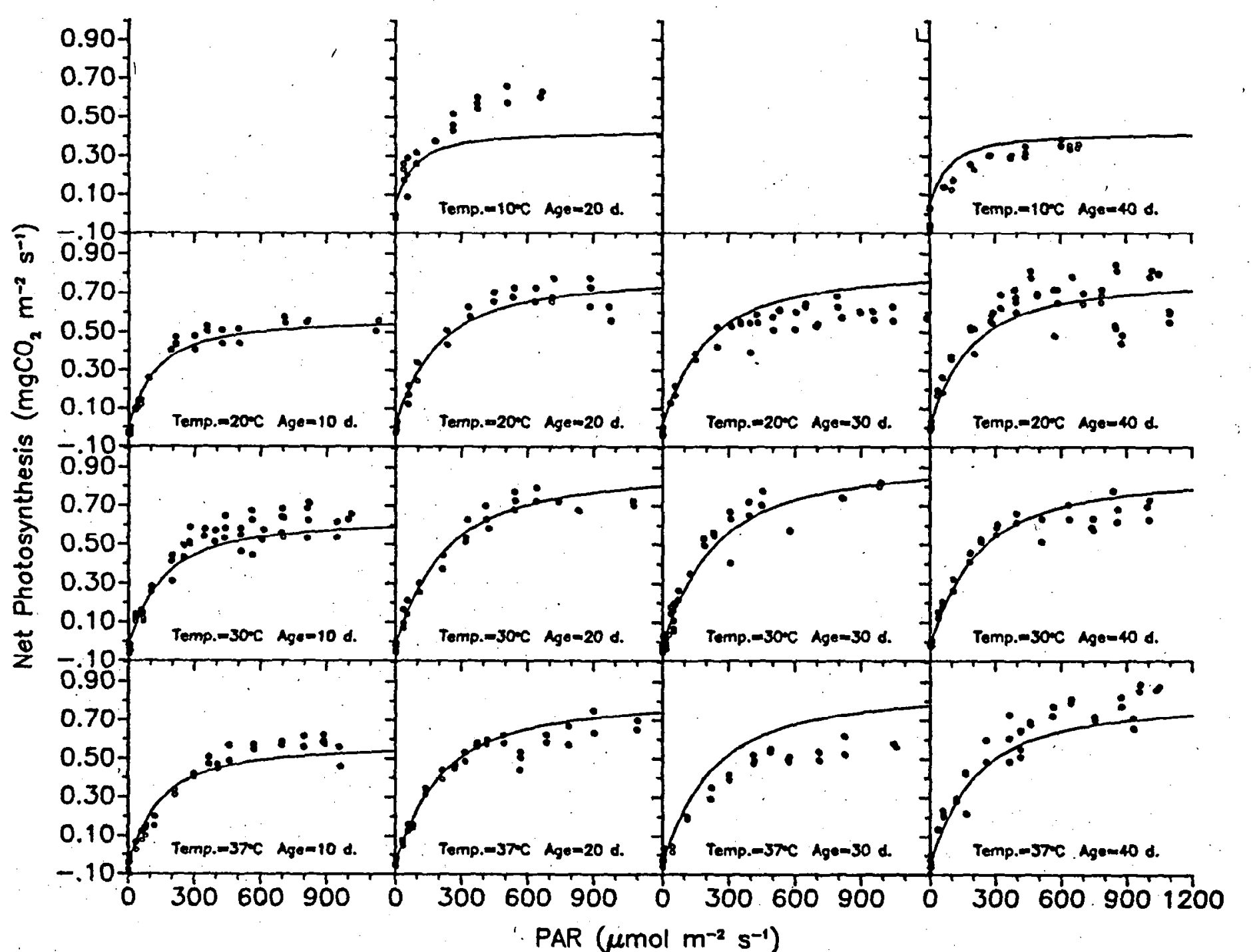

Fig. 3. Predicted (curves) and observed (circles) rose leaf net photosynthesis rates for leaves at 10, 20, 30, or 37C at leaf ages of 10, 20, 30, and 40 days.

cotton (Yamaguchi and Friend, 1979; Constable and Rawson, 1980), but not conclusively for roses (Pasian and Lieth, 1989). The replacement of $R_{d}$ in Eq. [1] with a function of $T$ and a, i.e., $\mathrm{R}_{\mathrm{d}}(\mathrm{T}, \mathrm{a})$, was also explored in this study.

Modeling the leaf temperature effect. Between 35 and 40C, the values of $\mathrm{P}_{\mathrm{m}}$ obtained indoors ranged between 0.6 and 0.8 $\mathrm{mg} \cdot \mathrm{s}^{-1} \cdot \mathrm{m}^{-2}$ (circles, Fig 1A), while those collected outdoors ranged from 1.0 to 1.1 (squares, Fig. 1A). This disparity (of unknown cause) precluded pooling the data. The data collected outdoors allowed estimation of the high temperature compensation point and the rate of decline of $\mathrm{P}_{\mathrm{n}}$ with high temperatures. Above $37 \mathrm{C}, \mathrm{P}_{\mathrm{m}}$ for the 20-day-old leaves decreased with a steep negative slope (Fig. 1B) to zero. As temperatures increased above $48 \mathrm{C}$, the leaf wilted and dried out rapidly resulting in permanent damage.

All net photosynthetic rates for PPFD above $600 \mu \mathrm{mol} \cdot \mathrm{s}^{-1} \cdot \mathrm{m}^{-2}$ below 37C for 20-day-old leaves increased with temperature up to $\approx 18 \mathrm{C}$ followed by a leveling between $18 \mathrm{C}$ and $35 \mathrm{C}$ (Fig. $1 \mathrm{~A})$. Above $35 \mathrm{C}$ the rate decreased. This pattern is consistent with the flat plateau observed by Bozarth et al. (1982).

Assuming the high-temperature denaturization process to be separate from the remaining temperature effects, $f_{1}(T)$ was ex- pressed as the product:

$$
f_{1}(T)=g_{1}(T) \cdot g_{2}(T)
$$

where $\mathrm{g}_{1}(\mathrm{~T})$ represents the reduction in $\mathrm{P}_{\mathrm{m}, \mathrm{T}, \mathrm{a}}$ for moderate and low, non-optimal temperatures, while $\mathrm{g}_{2}(\mathrm{~T})$ represents the denaturization effect. As with $\mathrm{f}_{1}(\mathrm{~T})$ and $\mathrm{f}_{2}(\mathrm{a}), \mathrm{g}_{1}(\mathrm{~T})$ and $\mathrm{g}_{2}(\mathrm{~T})$ must

elected so that their ranges are between 0 and 1 . The function $\mathrm{g}_{1}(\mathrm{~T})$ should have a flat plateau for $\mathrm{T}$ between 20 and $35 \mathrm{C}$ and a steep slope for $\mathrm{T}$ between 5 and 10C (Fig 1B). The equation

$$
g_{1}(T)=1 /\left(1+e^{b_{1}-b_{2}}\right),
$$

which satisfies these conditions, was used.

As temperatures rose above $40 \mathrm{C}$, the decline in net photosynthesis became very pronounced, so that above some high temperature $\left(\mathrm{T}_{\mathrm{d}}\right)$, the photosynthetic process was completely interrupted. The expression $1.0-\mathrm{e}^{\mathrm{b}} 3^{(\mathrm{Td}-\mathrm{T})} \mathrm{h}$ as this pattern in that it is less than, but almost equal to, 1.0 for moderate and low values of $\mathrm{T}$ where no denaturization occurs, while declining rapidly for $T$ approaching $T_{d}$. The rate of the onset of decline (degree of convexity) is determined by the parameter $b_{3}$. As- 

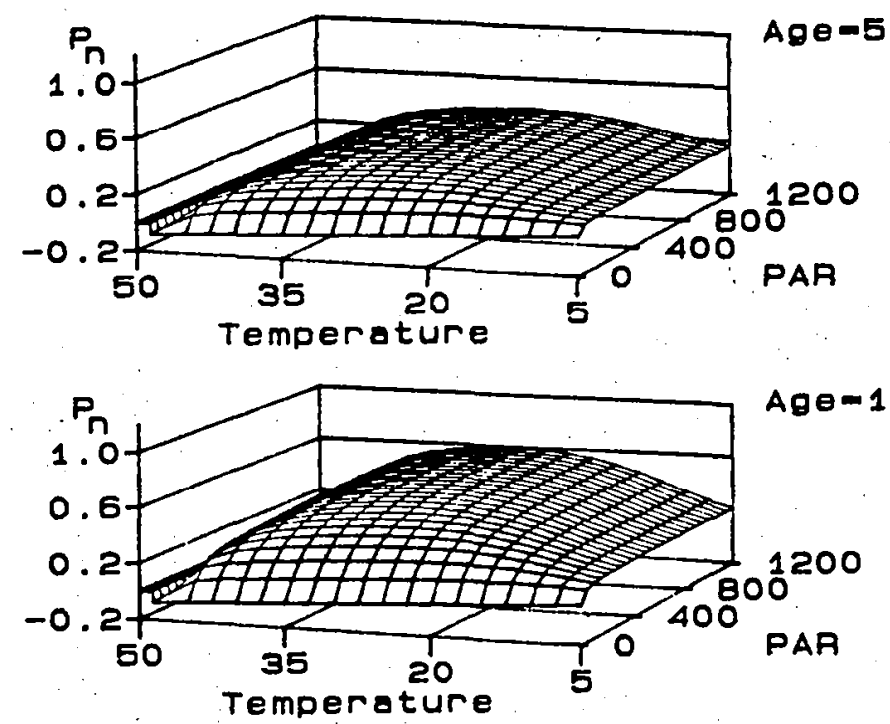

$\operatorname{Ag} \theta-10$

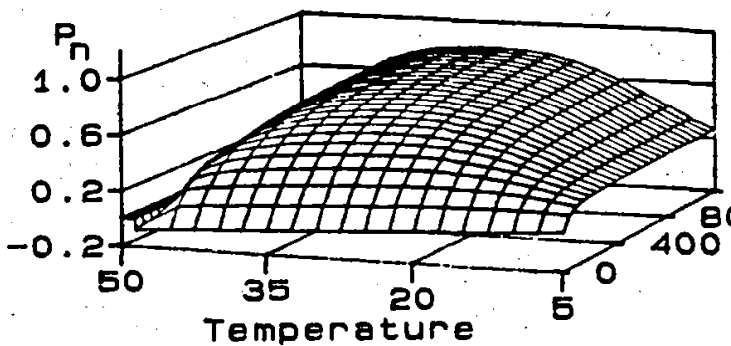

$A g e-20$
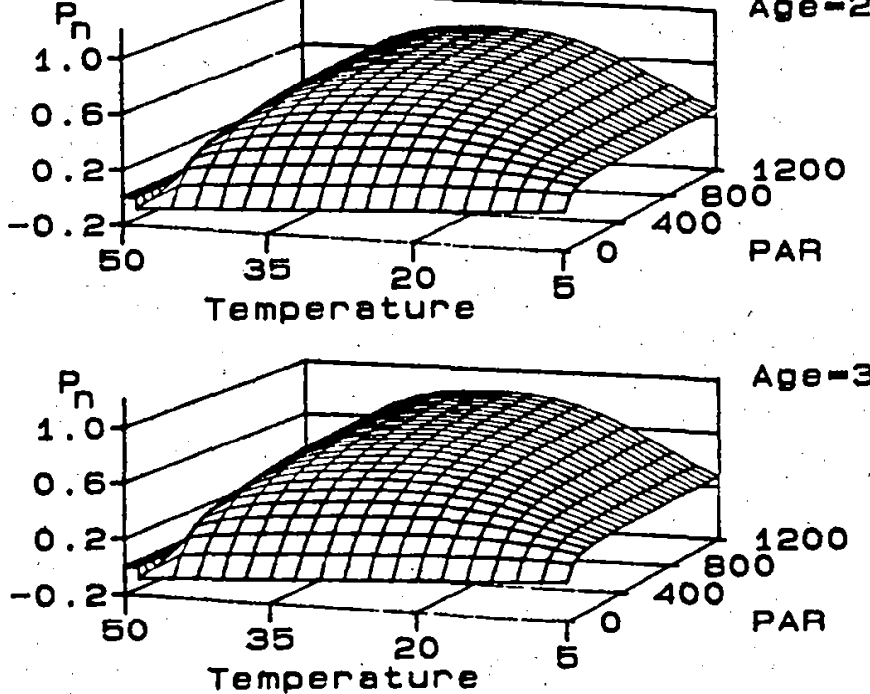
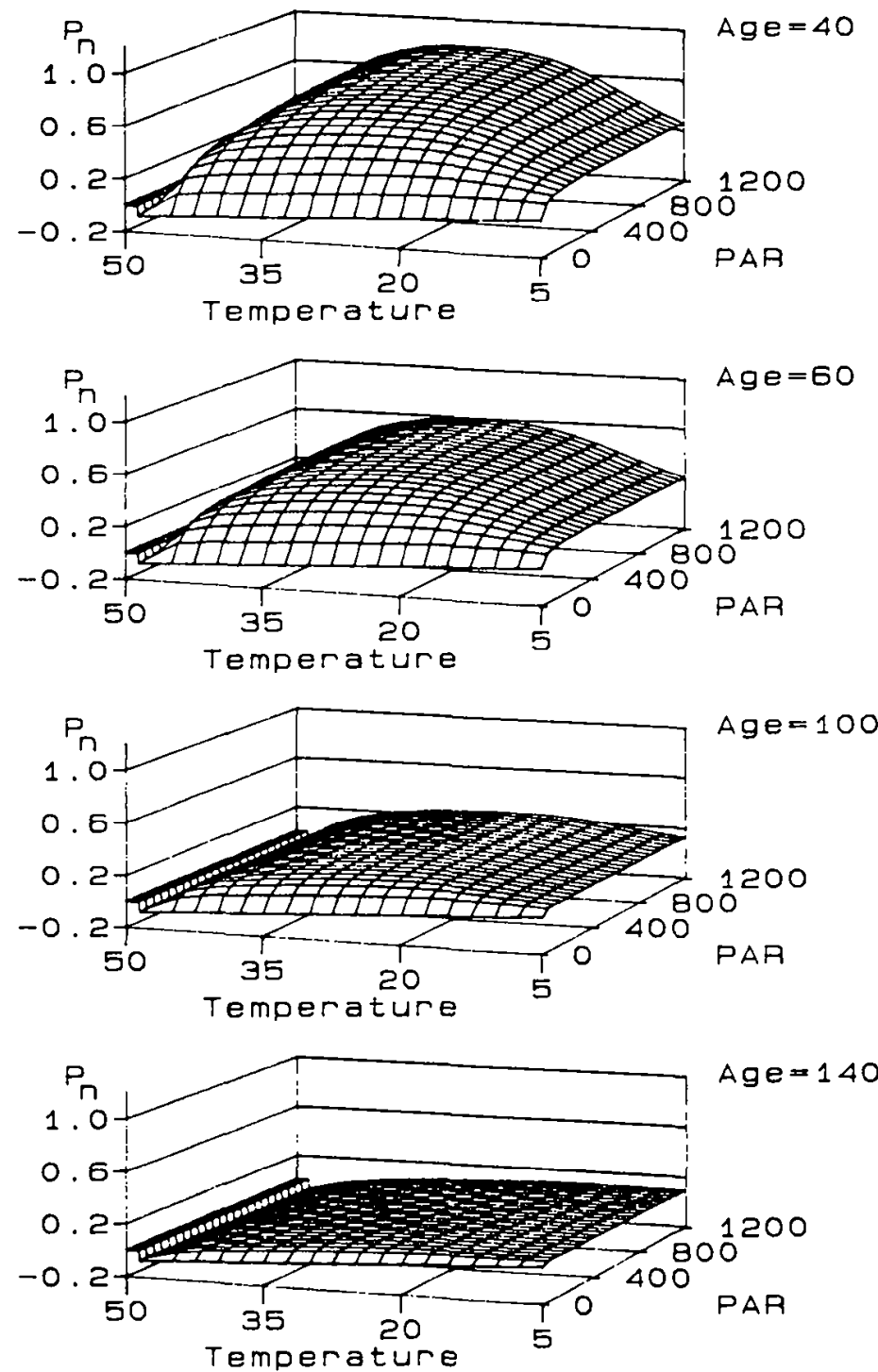

Fig. 4. Cross sections through the (four-dimensional) rose leaf photosynthesis surface at leaf ages of 5, 10, 20, 30, 40, 60, 100, and 140 days. Each three-dimensional cross section consists of the response surface for net photosynthesis $\left(\mathrm{mg} \cdot \mathrm{s}^{-1} \cdot \mathrm{m}^{-2}\right)$ as a function of leaf temperature $\left({ }^{\circ} \mathrm{C}\right)$ and photosynthetically active radiation $\left(\mu \mathrm{mol} \cdot \mathrm{s}^{-1} \cdot \mathrm{m}^{-2}\right)$.

suming no enzymatic activity for $T$ above $T_{d}$ resulted in the form

$$
g_{2}(T)= \begin{cases}1-e^{-b_{3}\left(T_{d}-T\right)} & \cdots T<T_{d} \\ 0 & \cdots T \geq T_{d}\end{cases}
$$

so that $\mathrm{f}_{1}(\mathrm{~T})$ has the desired shape (Fig. 1B).

Modeling the leaf age effect. $\mathrm{P}_{\mathrm{m}}$, as approximated by $\mathrm{P}_{\mathrm{n}}$ measurements at PPFD above $600 \mu \mathrm{mol} \cdot \mathrm{s}^{-1} \cdot \mathrm{m}^{-2}$, was low for young, rapidly expanding leaves, maximal at some intermediate age, followed by a gradual decline as leaves aged (Fig. 2). The increase for young leaves can be attributed to biochemical changes in the production of fully developed chloroplasts, including synthesis of a variety of molecules and increases in the total number of chloroplasts (Possingham, 1980; Leech and Baker, 1983). Reductions in photosynthetic rates as leaves age have been attributed to reductions in the concentrations of enzymes involved in the various photosynthetic reactions (Sestak, 1969; Hall and Brady, 1977; Zima and Sestak, 1979) and chloroplast mem- brane composition (Fong and Heath, 1977; Novitskaya et al., 1977). The function:

$$
f_{2}(a)=b_{4} a e^{1} \cdot a b_{4}
$$

was used since it has the desired shape (rapid increase to a maximum, gradual decline thereafter) and ranges between 0 and 1.0 (curve, Fig. 2).

Leaf dark respiration. In roses, $\mathrm{R}_{\mathrm{d}}$ has been shown to increase with temperature, while no conclusive pattern was observed with age (Pasian and Lieth, 1989). Respiration rates generally follow a convex pattern with temperature (Penning de Vries et al., 1979) that has been interpreted to be exponential (Gent and Enoch, 1983). Todaria (1986) observed linear increases with temperatures up to $45 \mathrm{C}$ in leaf samples of various subtropical species followed by a rapid decline between $45 \mathrm{C}$ and $55 \mathrm{C}$. Although a form more complex than a linear equation is likely to be appropriate for temperatures $<50 \mathrm{C}$, it could not be justified with the current data. Also, for temperatures above $T_{d}, R_{d}$ was 


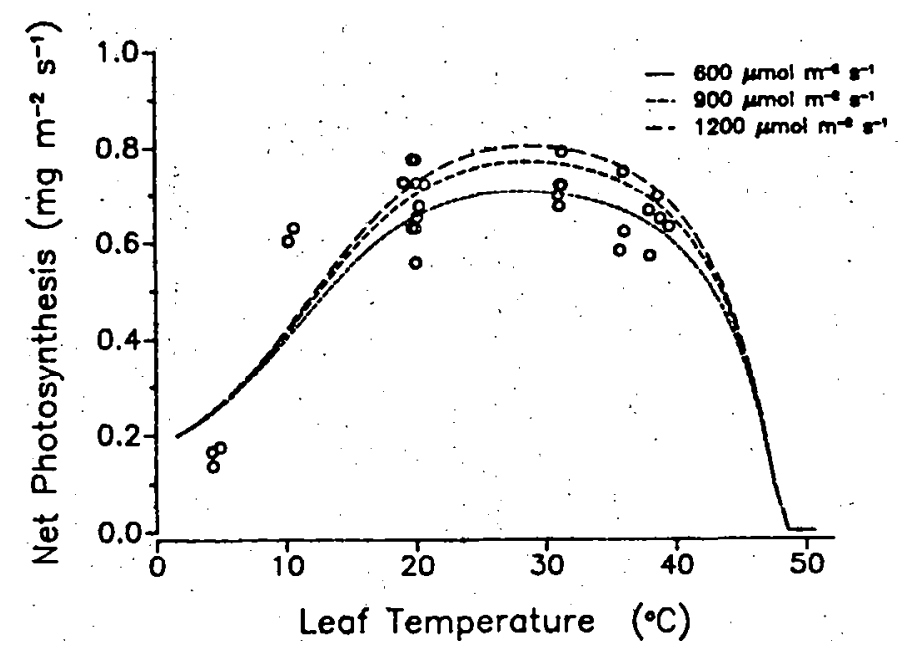

Fig. 5. Model predictions (curves) and observed (circles) net pbotosynthesis rates for 20-day-old leaves over a range of leaf temperatures at PPFD $>600 \mu \mathrm{mol} \cdot \mathrm{s}^{-1} \cdot \mathrm{m}^{-2}$.

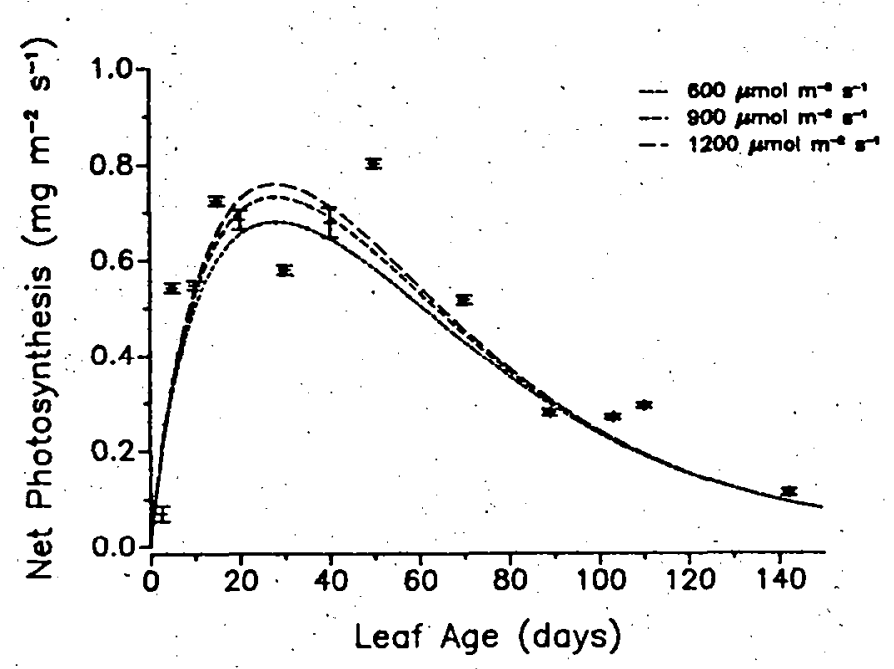

Fig. 6. Observed mean net photosynthesis rates (vertical bars represent SE) for leaves at 20C and PPFD levels between 600 and 750 $\mu \mathrm{mol} \cdot \mathrm{s}^{-1} \cdot \mathrm{m}^{-2}$. The predicted values (curves) are for exactly $20 \mathrm{C}$, while the observed date consist of observations for leaves between 18 and $22 \mathrm{C}$.

assumed to be zero due to the destruction of leaf tissue observed above this temperature. Thus, $\mathrm{R}_{\mathrm{d}}$ was represented as:

$$
R_{d}(T, a)=\left\{\begin{array}{l}
c_{0}+c_{1} T+c_{2} a \text { if } T \leq T_{d} \\
0 \quad \ldots \text { if } T>T_{d}
\end{array}\right.
$$

Leaf net photosynthesis model calibration. The individual components of the model (Eqs. [4]-[7]) were fit to the corresponding subsets of the data set with the nonlinear regression procedure, PROC NLIN, of the Statistical Analysis System (SAS Institute, 1987) to obtain preliminary estimates of all parameters. Combining Eqs. [1] through [7] resulted in the desired rose leaf net photosynthesis model that was then fit to the data using the preliminary parameter estimates as starting values. The data used for calibration included all previous (Pasian and Lieth, 1989) and newly measured data except for the data collected outdoors at extreme temperatures. Since no data were included with temperatures near or above $\mathrm{T}_{\mathrm{d}}$, its preliminary estimate, 48.6C, was assumed to be the correct value. During the initial fitting of the model, the value of $c_{2}$ was found to be $0.0 \pm$ $0.00028 \mathrm{mg} \cdot \mathrm{s}^{-1} \cdot \mathrm{m}^{-2} \cdot \mathrm{day}^{-1}$. Setting $\mathrm{c}_{2}$ to zero (i.e., removing the leaf age effect from the $R_{d}$ function) and refitting resulted in the parameter values shown in Table 1. This fit is highly significant with $97 \%$ of the total uncorrected sum of squares being accounted for by the model. All remaining parameters are significantly different from zero as indicated by the $95 \%$ confidence intervals.

\section{Discussion}

Grouping the accumulated $\mathrm{P}_{\mathrm{n}}$ data by the four leaf ages: 10, 20, 30, and 40 days, and four temperatures: 10, 20, 30, and $37 \mathrm{C}( \pm 2 \mathrm{C})$, allows comparison of the predicted and observed $P_{n}$ rates (Fig. 3). On the whole, the model predicts all observed PAR response data satisfactorily, although substantial overestimation occurs for 30-day-old leaves at 20 and 37C, while underestimation occurs for one case 20-day-old leaves at 10C). Such deviations are not unexpected because the model assumes uniform conditions and plant material, while the data includes variation attributable to inter-plant variability, slight fluctuations in calibration of the photosynthesis meter, and leaf area measurement errors.

A sequence of three-dimensional plots (Fig.. 4) illustrates the changes in the photosynthetic response to temperature and irradiance with leaf age. At all ages, the temperature response is fairly flat between 20 and $35 \mathrm{C}$, while the PAR cross section is always the saturation response of Eq. [1]. Above 48.6C the denaturization response is evident $\left(\mathrm{P}_{\mathrm{n}}=0\right)$. Between $45 \mathrm{C}$ and $\mathrm{T}_{\mathrm{d}}$, the net photosynthesis rate is negative, as gross photosynthesis rates become low while $R_{d}$ continues to increase.

Another check on how well the model behaves is to compare the measured photosynthetic rates at PAR near saturation with the model predictions. The leaf temperature pattern for $\mathrm{P}_{\mathrm{n}}$ of 20-day-old leaves at high PAR (Fig. 5) is not as flat as was originally anticipated, probably because of the paucity of data for temperatures $\leq 10 \mathrm{C}$. The parameters $b_{1}$ and $b_{2}$ are responsible for this behavior. With additional data at low temperatures, model calibration would probably result in different values for $b_{2}$, and possibly $b_{1}$, with smaller confidence intervals.

The model also could be improved by replacement of Eq. [7] with a more mechanistic description. The current selection is the simplest possible expression. The values of $\mathrm{c}_{0}$ and $\mathrm{c}_{1}$ result in negative values for $R_{d}$ for low $T$ resulting in a slight positive bias in $\mathrm{P}_{\mathrm{n}}$ for low $\mathrm{T}$. This aberration is probably due to the equipment used in this study not being sensitive enough to measure respiration accurately.

The estimated values of $\mathrm{P}_{\mathrm{n}}$ for high PAR over leaf age for leaves at 20C represent the trend in the data well (Fig. 6). The considerable variation about the predictions suggests that chronological time may not be the best way to represent leaf age. A physiological time variable, such as heat units, might be a more suitable measure. Also, the model does not incorporate acclimation and adaptation effects that may cause leaves of the same age to have different photosynthetic capacities depending on environmental conditions in the days or weeks before the measurement.

Model extensions to include additional effects, such as $\mathrm{CO}_{2}$ concentration, can be accomplished in the same way that leaf temperature and age were added here. Equation [2] is then replaced with a product of the overall maximum $\mathrm{P}_{\mathrm{m}}$ over all variables and functions for each variable. Data would, of course, have to be collected over a wide range of all the variables. Mathematical equations for these functions could be formulated 
to provide the flexibility needed to validly represent the response of net photosynthesis at saturating PAR over the ranges of each variable. Subsequent recalibration would result in a predictive model for net leaf photosynthesis at all considered variables.

\section{Literature Cited}

Aikin, W.J. and J.J. Hanan. 1975. Photosynthesis in the rose; effect of light intensity, water potential and leaf age. J. Amer. Soc. Hort. Sci. 100:551-553.

Bozarth, C.S., R.A. Kennedy, and K.A. Schekel. 1982. The effect of leaf age on photosynthesis in rose. J. Amer. Soc. Hort. Sci. 107:707712.

Catsky, J. and I. Ticha. 1980. Ontogenetic changes in the internal limitations to bean-leaf photosynthesis. Photosynthetica 14:392-400.

Constable, G.A. and H.M. Rawson. 1980. Effect of leaf position, expansion and age on photosynthesis, transpiration and water use of cotton. Austral. J. Plant Physiol. 7:89-100.

Gent, M.P.N. and H.Z. Enoch. 1983. Temperature dependence of vegetative growth and dark respiration: a mathematical model. Plant Physiol. 71:362-567.

Field, C. and H.A. Mooney. 1983. Leaf age and seasonal effects on light, water, and nitrogen use efficiency in a California shrub. Oecologia (Berlin) 56:348-355.

Fong, F. and R.L. Heath. 1977. Age dependent changes in phospholipids and galactolipids in primary bean leaves (Phaseolus vulgaris). Phytochemistry 16:215-217.

Hall, A.J. and C.J. Brady. 1977. Assimilate source-sink relationship in Capsicum annuum L. II. Effects of fruiting and defloration on the photosynthetic capacity and senescence of leaves. Austral. J. Plant Physiol. 4:771-783.

Johnson, I.R. and J.H.M. Thornley. 1984. A model of instantaneous and daily canopy photosynthesis. J. Theor. Biol. 107:531-545.

Leech, R.M. and N.R. Baker. 1983. The development of photosynthetic capacity in leaves, p. 271-307; In: J.E. Dale and F.L. Milthorpe (eds.). The growth and functioning of leaves. Cambridge University Press, Cambridge, U.K.

Marshall, B. and P.V. Biscoe. 1980. A model for $\mathrm{C}_{3}$ leaves describing the dependence of net photosynthesis on irradiance. I. Derivation. J. Expt. Bot. 31:29-39.

Novitskaya, G.V., L.A. Rutskaya, and Y.G. Molotkovskii. 1977. Age changes of lipid composition and activity of the membranes in bean chloroplasts. Fiziologia Rastenii 24:35-43.

Pasian, C.C. and J.H. Lieth. 1980. Analysis of the response of net photosynthesis of rose leaves of varying ages to photosynthetically active radiation and temperature. J. Amer. Soc. Hort. Sci. 114(4):581586.

Penning de Vries, F.W.T., J.M. Witlage, and D. Kremer. 1979. Rates of respiration and increase in structural dry matter in young wheat, ryegrass and maize plants in relation to temperature, to water stress, and to their sugar content. Ann. Bot. 44:595-609.

Possingham, J.V. 1980. Plastid replication and development in the life cycle of higher plants. Annu. Rev. Plant Physiol. 31:113-129.

Reynolds, J.F., B. Acock, R.L. Dougherty, and J.D. Tenhunen. 1989. A modular structure for plant growth simulation models, p. 123134. In: J.S. Pereira and J.J. Landsberg (eds.). Biomass production by fast growing trees. Kluwer Academic, Boston, Mass.

SAS Institute. 1987. The NLIN procedure. SAS/STAT guide for personal computers, Version 6 ed. SAS Institute Inc., Cary, N.C. p. 675-712.

Sestak, Z. 1969. Ratio of photosystem one and two particles in young and old leaves of spinach and radish. Photosynthetica 3:285-287.

Todaria, N.P. 1986. Respiration rates of some greenhouse cultivated tropical and subtropical species. Biol. Plant. (Praha) 28:280-287.

Thornley, J.H.M. 1976. Mathematical models in plant physiology. Academic, London.

Whisler, F.D., B. Acock, D.N. Baker, R.E. Fye, H.F. Hodges, J.R. Lambert, H.E. Lemon, J.M. McKinion, and V.R. Reddy. 1986. Crop simulation models in agronomic systems. Adv. Agron. 40:141208.

Yamaguchi, T. and D.J.C. Friend. 1979. Effect of leaf age and irradiance on photosynthesis of Coffea arabica. Photosynthetica 13:271278.

Zima, J. and Z. Sestak. 1979. Photosynthetic characteristics during ontogenesis of leaves: 4. Carbon fixation pathways, their enzymes and products. Photosynthetica 13:83-106. 